\title{
Story, Metaphor, and Altruism in Cross-Cultural Teaching and Learning
}

\author{
Michael P. Black ${ }^{1,2 * t}$, Andy M. Kazama ${ }^{3,4 t}$, Kalden Gyatso ${ }^{5}$ and Thukten Dema ${ }^{6}$ \\ ${ }^{1}$ Neuroscience Institute, Georgia State University, Atlanta, GA, United States, ${ }^{2}$ Urban Studies Institute, Georgia State \\ University, Atlanta, GA, United States, ${ }^{3}$ Psychology Department, Emory University, Atlanta, GA, United States, ${ }^{4}$ Division of \\ Developmental Cognitive Neuroscience, Yerkes National Primate Research Center, Atlanta, GA, United States, ${ }^{5}$ Sera Jey \\ Monastery, Bylakuppe, India, ${ }^{6}$ Jangchub Choeling Nunnery, Kusur, India
}

OPEN ACCESS

Edited by:

Meena M. Balgopal, Colorado State University,

United States

Reviewed by:

Anna F. Edlund,

Bethany College, United States

Jacob Shreckengost,

Craig H. Neilsen Foundation,

United States

Kelsey Marie Gray,

Chapman University, United States

Savitha Moorthy,

Tandem, Partners in Early Learning,

United States

${ }^{*}$ Correspondence:

Michael P. Black

seawater@gsu.edu

tThese authors have contributed equally to this work and share first authorship

Specialty section: This article was submitted to Science and Environmental Communication, a section of the journa Frontiers in Communication

Received: 28 July 2021 Accepted: 21 January 2022

Published: 21 February 2022

Citation:

Black MP, Kazama AM, Gyatso K and Dema T (2022) Story, Metaphor, and Altruism in Cross-Cultural Teaching and Learning.

Front. Commun. 7:749012 doi: 10.3389/fcomm.2022.749012
The Emory-Tibet Science Initiative (ETSI) is a cross-cultural exchange of Western and Tibetan Buddhist education and scholarship. In this partnership between the Dalai Lama Foundation and Emory University, two visiting Western scientists to Sera, Gaden, and Drepung Monasteries and two monastics who studied at Emory University reflect on their experiences teaching and learning from Western and Buddhist perspectives as part of the ETSI program. Specifically, authors explore the power of story, metaphor, and altruism in Buddhist and Western ways of teaching and learning. Authors consider the pedagogical similarities between (1) the variations of the Greek Method of Loci (Memory Palace) and the paintings and temple decorations found throughout Tibetan architecture and (2) the role of altruism and intrinsic motivation in learning outcomes. Current psychological and neurobiological evidence for the increased recall of episodic memories present in both Buddhist and Western use of story, metaphor, and intrinsic motivation associated with altruism will highlight the underlying principles that support these ancient methods. Finally, considerations on how each perspective informs the other is discussed, as well as practical suggestions for integrating methods across cultures.

Keywords: intrinsic motivation, curiosity, narrative, pedagogy, contemplative, Buddhism, Dalai Lama, science education

\section{OPENING DEDICATION:}

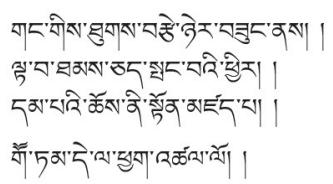

I pay homage to Gautama Buddha,

Who, completely driven by compassion,

Taught sublime Dharma

To dispel all the wrong views.

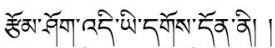

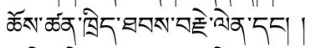

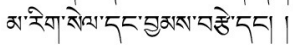

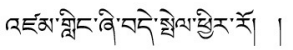


The purpose of composing this article is to exchange teaching methods of Buddhism and science,

To clear away intellectual misconceptions and wrong views,

And to promote compassion and peace in the world.

\section{INTRODUCTION}

This article, framed by prayer elements of a traditional Tibetan debate, is a collaboration of Buddhist Monastic scholars and Western-trained neuroscientists, all members of the EmoryTibet Science Initiative (ETSI). In these types of cross-cultural interactions, it is important to keep in mind Pratt (1991)'s contact zones and the negative effects of cultural appropriation. Rather than advocating political stances or telling others how to teach, the novelty of this reflection is the cross-cultural collaboration of ETSI authors to generate an appreciation for how mutual integration of pedagogical styles leads to a more holistic community of scholars. Indeed, ETSI is, "a unique educational endeavor, bringing together the best of the Western and Tibetan Buddhist intellectual traditions for their mutual enrichment and for the discovery of new knowledge" with programs to "explore the convergence of science and inner values in an effort to address humanity's greatest problems on more than a material level" (Emory-Tibet Science Initiative, 2021). Each author has invested time teaching and learning with both Tibetan Buddhist practitioners and Western scholars in their native and non-native institutions (Jangchup Choeling Nunnery, Sera Monastery, Emory University, and Georgia State University). This crosscultural exchange has shaped our thinking and this contribution. Prior to our involvement in ETSI, we could not appreciate the many complementary aspects of Tibetan Buddhism and Western science. ETSI's cross-cultural exchanges have been far-reaching both intellectually and geographically, and we hope they have contributed to the timely vision of increasing kindness and compassion throughout the world. Thus, it is with tremendous gratitude that we pay our respects to His Holiness, The 14th Dalai Lama, and his successful effort to connect thousands of Buddhist scholars with scientists around the world. Our collaborative connection will reflect on comparative pedagogical methods that may shed light on the use of story and metaphor as a convergent principle observed both in early Western teaching traditions, dating back to the roots of Greek philosophy (Aristotle, ca. 350 B.C.E.; Yates, 1966), and ancient Tibetan Buddhist traditions. Despite the deep historic roots of these methods, current knowledge in neuroscience has only recently allowed us to begin to understand the neural underpinnings of story and metaphor as pedagogical methods. This paper describes an empiricallysupported approach used by ETSI Scholars to integrate the use of story, metaphor, and altruism's intrinsic motivation to help others across Tibetan Buddhist studies and neuroscience education. This paper begins with story and metaphor and the neuroscience associated with these pedagogies and then focuses on internal motivation and altruism. Both Western and Tibetan scholars have benefited from their shared realizations about commonalities. The commonalities may have always existed, but through consideration and discussion, the four authors are now aware of them, see their utility more clearly, and can more intentionally use and emphasize them in future classrooms.

\section{STORY IN TEACHING AND LEARNING}

Entering a Buddhist temple, the Western neuroscientists among us were immediately awed by the wall-to-wall artwork. The neuroscientists did not fully understand just how many layers of meaning were embedded into each artistically rendered story. Similar to the early Greek Method of Loci (Memory Palace), a memory technique based on tying information to spatial locations, each intentionally placed piece of art serves as a mnemonic aid imbued with deeper cosmological lessons. The entrances of Tibetan Buddhist monasteries often feature a painting called the "Bhavacakra," or "Wheel of Life" (Figure 1). More than just a beautiful painting, the Bhavacakra depicts Yama, the god of death, holding a mirror up to a human at the moment of their death. The wheel within the mirror represents the nature of life, death, and rebirth according to one's Karma. These painted stories are used to teach the fundamental aspects of Buddhism and can be found in virtually all Tibetan Buddhist temples. Lay people will be able to describe simplistic concepts (e.g., the pig represents ignorance, the snake represents hatred, and the pigeon represents attachment), but monastic scholars derive far deeper and more complicated information from the same painting. For example, in the image, the snake emerges from the mouth of the pig. This artistic representation references deeper scriptural lessons wherein the root of anger comes out of ignorance. Additionally, the painting serves as a mnemonic device to study the many other sources of anger. Thus, the "Wheel of Life" takes on philosophical layers with each aspect of the painting available for deeper reflections. Buddhist Scholars will spend a lifetime connecting the artwork with scriptures and teachings. Could this phenomenal pedagogical tool inspire Western practitioners to adopt complex layered stories for teaching scientific concepts?

Like the "Wheel of Life," Western scientific graphs convey complex layers of information, telling a story with their data descriptions. As Western teaching content often involves physical phenomena, illustrations and videos help visualize and explain information. This media surpasses text descriptions in the ability to convey complexities and new knowledge, and so much digital media is readily available on the internet. The Tibetan monastics among us plan to integrate graphs, videos, and images into their teaching. A major concern within current Western pedagogy is overreliance on these videos and images rather than varying pedagogical techniques (Lang, 2020). These variations could include Eastern approaches and interactive uses of story and metaphor.

\section{METAPHOR IN TEACHING AND LEARNING}

Metaphor is seen in the Buddhist "Wheel of Life" as a daily practice as Buddhists enter the temple. The mirror held by Yama, the god of death, is a metaphor that serves as a reminder for selfreflection. The moon, which lies outside the mirror, is a metaphor representing the freedom of enlightenment in breaking out of the 


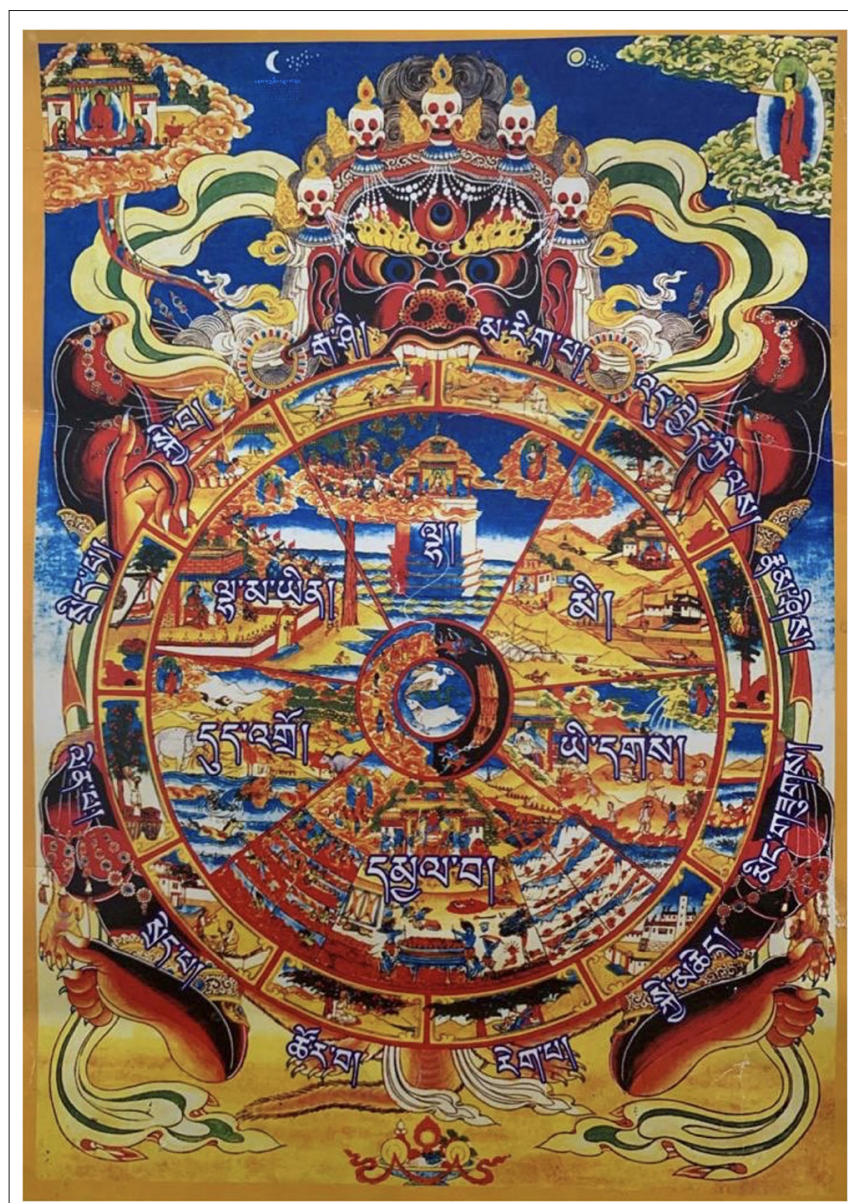

FIGURE 1 | Bhavacakra (Wheel of Life). Held by Yama, the god of death, the wheel within the mirror represents the nature of life, death, and rebirth according to one's karma. Image provided with permission by Lobsang Dorje.

cycle of life and death. Thus, metaphors in Buddhist teaching are a key pedagogical tool.

The use of metaphor as a pedagogical tool in Western teaching can be traced back to the earliest Greek teachers, although the origin of their use is almost certainly earlier. Arguably, one of the most famous uses of metaphor is Plato's Cave (Plato Republic, 2009). Here Plato questions the nature of reality, contrasting the shadows cast onto a cave with the richer reality that awaits those philosophers pursuing the true nature of the universe.

ETSI Scholar Dr. Kazama has adapted the use of metaphors into an Introduction to Psychobiology and Cognition Course wherein the neuron becomes a multi-layered metaphor for life. In a more traditional introduction, neurons are brain cells that form neural networks found throughout the nervous system. Neurons use a process known as the "action potential" to send signals down the length of the cell. A relatively simple lecture on the basic properties of a neuron's action potential (Figure 2) can be taught through the strict lens of biology, physics, and chemistry (e.g., the structure of the neuron and the exchange of positive and negatively charged ions). However, such basic STEM lessons take on new vibrancy when other disciplines become integrated, and the neuron becomes a metaphor for life. Students are encouraged to derive deeper philosophical meaning as they are challenged to use the neuron's action potential as a fractallike construct for human psychology. The individual neuron and its struggle between balance and growth are investigated as a microcosm for life. The "resting" phase takes on new significance as students realize that very little "rest" is occurring, rather that the neuron is constantly grinding to maintain its polarized state while being pulled toward electrical equilibrium. New intrinsic interest in the material is achieved when students visualize their own neurons pulled toward a balanced state but only achieving true balance for brief moments. This is much closer to a students' daily life, and students find solace knowing that every neuron in their head is built with that feature. Additionally, the properties of long-term potentiation (LTP), critical for forming memories, are given a multidisciplinary framework as ancient Greek mnemonic techniques (e.g., Memory Palace) and modern neuroscience insights about the strength of emotional memories [for review, see Hamann (2001)] complement the microscopic inner workings of a neural network undergoing LTP. Similar to the Tibetan Buddhist teachings where each moral lesson is represented through art and story, Simonides, described by Cicero as the creator of the Memory Palace, undergoes LTP as he rehearses the location of each family member buried in the palace's rubble (Cicero et al., 1942). While certainly a less complex lesson than the "Wheel of Life," the action potential has the ability to take on a multidisciplinary layered structure that is analogous to the pedagogical use of story and metaphor used in Tibetan Buddhist temples. This metaphorical approach has received very positive course reviews. More importantly, the modern application of this ancient methodology of metaphor has many qualities that have been empirically shown to increase student memory retention [for reviews on storytelling in STEM, see Klassen (2010) and Dahlstrom (2014)]. In addition to the memory benefits of the emotional content (Hamann, 2001), both the "Wheel of Life" and the example of the action potential lesson contain a first-person perspective. The "Wheel of Life" depicts a mirror held up to the viewer, and the neuroscience course relies heavily on introspection with each students' brain studying itself. While not taken as far as contemplative pedagogy (Zajonc, 2013), students are intrinsically motivated to learn the material and connect lessons in a multidisciplinary fashion through metaphorical pedagogy.

\section{NEURAL UNDERPINNINGS FOR STORY AND METAPHOR IN TEACHING AND LEARNING}

Both metaphor and story can enhance the emotional content of what is being learned by relating to the learner's existing framework of knowledge and to something that matters to the learner. Emotion strongly influences attention, an important early step in learning and memory (Tyng et al., 2017; Lang, 2020). Emotional memories are encoded and retrieved with involvement of the amygdala and medial temporal lobe structures (e.g., entorhinal and perirhinal cortex and hippocampus), as well as the putamen, insula, orbitofrontal cortex, and ventral visual stream [reviewed in Dahlgren et al. (2020)]. Other 


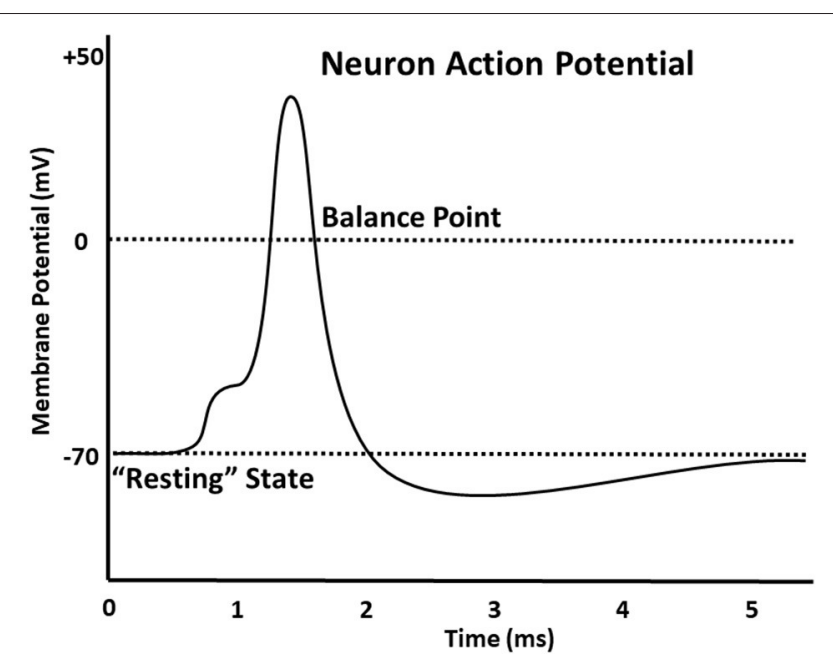

FIGURE 2 | Neuron action potential. Teaching graphic used to describe changes in the electrical balance of a stimulated neuron over time.

regions involved in emotional episodic memory retrieval are also involved in retrieval of emotional memory (e.g., dorsal frontal cortex) and episodic memories (e.g., angular gyrus; Dahlgren et al., 2020). Some of these same brain areas are involved in processing figurative language like metaphor. For instance, controlling for language complexity and compared to literal material, figurative language results in higher levels of activity in the anterior portion of the left hippocampus and the amygdala (particularly the left amygdala; Bohrn et al., 2012; Citron and Goldberg, 2014). Co-activation of the hippocampus and amygdala has also been associated with retrieval of emotional memories a year later (Dolcos et al., 2005).

The long-term memory of story components over the course of minutes correlates with coupling of activity in areas of the brain's default mode network, or DMN (Simony et al., 2016; review of the DMN: Raichle, 2015). With story, storyteller and listener show similar brain activity, including in areas of the DMN, and how well the areas couple correlates with comprehension of the story (Stephens et al., 2010; Silbert et al., 2014). For the same story, we see similar brain activity patterns for different individuals recalling the story, even if they differed in their native language the story was told in (Honey et al., 2012; Dehghani et al., 2017) or read text or watched a movie of the story instead of hearing it (Regev et al., 2013; Baldassano et al., 2017; Chen et al., 2017; Tikka et al., 2018; Wilson et al., 2018). Based on many research studies, Yeshurun et al. (2021) posit that over long timescales the DMN integrates new information from stories with prior knowledge.

\section{INTRINSIC MOTIVATORS AND ALTRUISM}

Like story and metaphor, intrinsic motivation is associated with enhanced memory and increased conceptual learning [reviewed by Ryan and Deci (2020)]. Classroom use of intrinsic motivation to increase memory and attention is not a new concept, but we want to reinvigorate the use of intrinsic motivation to balance heavy extrinsic motivation (e.g., grades) in Western teaching (Lang, 2020; Bain, 2021). In teaching, altruism's intrinsic motivation can be fostered by relating material to things learners care about, whether a story's protagonist, a family member, or a life passion. ETSI Scholar Dr. Black uses this idea in his Scientific Method in Neuroscience class. Students pick their own topics to critically evaluate the scientific literature. This autonomy is associated with enhanced student performance (Ryan and Deci, 2020). Whether their topic is video game effects on the brain or a family member's neurological disease, excited students dig more deeply into the topic than they would if it were an assigned topic. In Dr. Black's Neuroscience Laboratory, students test their hypotheses on small projects of their own design after learning techniques. The laboratory course culminates with a final project of a student group's conception and design. The students have autonomy and ownership by submitting their own proposal for approval and modification, conducting their experiment, and presenting it in a poster session to the full departmental faculty. Higher intrinsic motivation to learn generates higher activity in the midbrain and nucleus accumbens and enhanced memory (Gruber et al., 2014). The more memory is enhanced, the higher the anticipatory activity in the midbrain (substantia nigra/ventral tegmental area complex) and hippocampus and the greater the functional connectivity between them with intrinsic motivation (Gruber et al., 2014).

The importance of intrinsic motivation was reinforced for Dr. Black through the ETSI experience. The experience also inspired course incorporation of stories and studies of compassion in neuroscience as well as encouragement of students to select assignment topics to help a friend or family member. Students can have strong motivation for their projects when fueled by the altruistic goal of learning more about or helping someone they care about.

Altruism can also be fostered in scientific courses by human connection. In his very first undergraduate neuroscience course with his professor, Dr. Julio Ramirez, Dr. Kazama experienced this effect. The initial class exercise was a powerful visit to an Alzheimer's clinic to interview a patient with advanced Alzheimer's disease. Upon seeing the devastating effects of this neurodegenerative disorder, the altruistic motivation to help others was instantiated and remains a major driving factor over 20 years later.

In the Tibetan monastic tradition, virtually every dharma lesson begins and ends with prayers by the students and teacher to promote an altruistic intrinsic motivation for learning. Buddhists train to develop compassion and empathy, increasing altruism, and there is much to learn in that development for Western application. One example of Western application is cognitive-based compassion training (CBCT), collaboratively developed at Emory University and based on Indo-Tibetan Buddhist traditions (Ash et al., 2021). Following CBCT, students showed higher empathic accuracy and increased compassion (Mascaro et al., 2013, 2018). Greater compassion can increase altruism and the internal motivation to teach and learn. 


\section{CONCLUDING CROSS-CULTURAL INSIGHTS}

Clearly Western science can benefit from shared aspects of Tibetan Buddhist pedagogy, but the reverse is also true. The scientific method is complementary to the logic-driven study and debate of scriptural texts by Buddhist scholars. ETSI Scholars Monk Kalden and Nun Thupten agree that focusing on hypothesis testing and empirical case studies will enhance their approach. They greatly appreciated the hands-on learning aspects of Western pedagogy with active collection and analysis of data to better understand the process of science and the scientific concepts under investigation. In most Tibetan monasteries, the most common form of learning is to memorize scriptures, read scriptural text, listen to scripture teachers, debate with classmates and teachers, and meditate. Monastics are already accustomed to using logic and reasoning to prove or disprove arguments, and this knowledge can be complemented by the scientific method, forming hypotheses and testing the hypotheses with experiments. Monk Kalden and Nun Thukten hope to implement active data collection and analysis, enabling students to build their own scientific stories.

Monk Kalden also plans to further foster student-led activities outside of the instructor-led classroom, motivating students to draw and take notes, encouraging group discussions and hands-on activities, and forming a WhatsApp or WeChat group to share notes, related videos, questions, metaphors, stories, and discussions on certain topics. These approaches further empower students and engage them in learning outside of class.

The ETSI partnership has been a unique educational endeavor. Both Eastern and Western scholars have benefited tremendously from immersing themselves in each other's educational systems and have been able to apply the pedagogical techniques described here to their own classrooms. In particular, the cross-cultural methods of story and metaphor are of benefit to students and enhance the interdisciplinary aspects of our respective fields. Of even greater importance, the central role of altruistic intentionality has been a major contribution by our Tibetan monastic colleagues. Supported by empirical data, the interdisciplinary nature of story, metaphor, and altruistic motivation provides multiple ways to access neuroscience for both Tibetan monastics and Western students alike. This will certainly lead to more effective and compassionate scholars, one of the major goals of ETSI. We close by again paying our respects

\section{REFERENCES}

Ash, M., Harrison, T., Pinto, M., Diclemente, R., and Negi, L. T. (2021). A model for cognitively-based compassion training: theoretical underpinnings and proposed mechanisms. Soc. Theor. Health 19, 43-67. doi: $10.1057 /$ s41285-019-00124-x

Bain, K. (2021). Super Courses: The Future of Teaching and Learning. Princeton, NJ: Princeton University Press.

Baldassano, C., Chen, J., Zadbood, A., Pillow, J. W., Hasson, U., and Norman, K. A. (2017). Discovering event structure in continuous narrative to His Holiness, without whom this fruitful collaboration would not be possible.

DEDICATION:

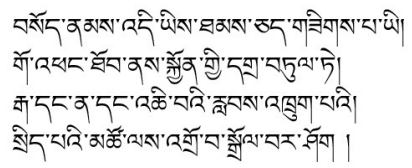

Through this effort, May all attain enlightenment, And by defeating the foe of negative emotions

May all beings be freed from the ocean of samsara (cyclic existence)

Which is ravaged by the waves of aging, sickness, and death.

\section{DATA AVAILABILITY STATEMENT}

The original contributions presented in the study are included in the article/supplementary material, further inquiries can be directed to the corresponding author/s.

\section{AUTHOR CONTRIBUTIONS}

$\mathrm{MB}, \mathrm{AK}, \mathrm{KG}$, and TD contributed to the ideas of the manuscript and wrote sections of the manuscript. $\mathrm{MB}$ and $\mathrm{AK}$ wrote the first draft of the manuscript. All authors contributed to manuscript revision, read, and approved the submitted version.

\section{FUNDING}

All authors received funding from the Emory-Tibet Science Initiative. The Emory-Tibet Science Initiative (ETSI) funded the printing costs of this article. ETSI also covered logistics, travel costs, and accommodations for the Western scientists to teach and learn at Sera Monastery and in India. ETSI covered logistics, travel, accommodations, and tuition for the monastics to teach and learn at Emory University in the United States.

\section{ACKNOWLEDGMENTS}

The authors want to thank the Emory-Tibet Science Initiative and His Holiness, The 14th Dalai Lama for making this possible. We also thank our early reviewers, Joonna Trapp at Emory University, Ken Bain at Best Teachers Institute, Melissa and Judy Black, and Sarah Clark, Marise Parent, and Nancy Forger at Georgia State University.

Bohrn, I. C., Altmann, U., and Jacobs, A. M. (2012). Looking at the brains behind figurative language - a quantitative meta-analysis of neuroimaging studies on metaphor, idiom, and irony processing. Neuropsychologia 50, 2669-2683. doi: 10.1016/j.neuropsychologia.2012. 07.021

Chen, J., Leong, Y. C., Honey, C. J., Yong, C. H., Norman, K. A., and Hasson, U. (2017). Shared memories reveal shared structure in neural activity across individuals. Nat. Neurosci. 20, 115-125. doi: 10.1038/nn.4450 
Cicero, M. T., Sutton, E. W., and Rackham, H. (1942). De oratore; De fato; Paradoxa stoicorum; De partitione oratoria. Cambridge, MA: Harvard University Press. doi: 10.4159/DLCL.marcus_tullius_cicero-de_partitione_oratoria.1942

Citron, F. M. M., and Goldberg, A. E. (2014). Metaphorical sentences are more emotionally engaging than their literal counterparts. J. Cogn. Neurosci. 26, 2585-2595. doi: 10.1162/jocn_a_00654

Dahlgren, K., Ferris, C., and Hamann, S. (2020). Neural correlates of successful emotional episodic encoding and retrieval: an SDM metaanalysis of neuroimaging studies. Neuropsychologia 143, 107495. doi: 10.1016/j.neuropsychologia.2020.107495

Dahlstrom, M. F. (2014). Storytelling in science. Proc. Natl. Acad. Sci. U. S. A. 111(Suppl.4), 13614-13620. doi: 10.1073/pnas.1320645111

Dehghani, M., Boghrati, R., Man, K., Hoover, J., Gimbel, S. I., Vaswani, A., et al. (2017). Decoding the neural representation of story meanings across languages. Hum. Brain Map. 38, 6096-6106. doi: 10.1002/hbm.23814

Dolcos, F., LaBar, K. S., and Cabeza, R. (2005). Remembering one year later: role of the amygdala and the medial temporal lobe memory system in retrieving emotional memories. Proc. Natl. Acad. Sci. U. S. A. 102, 2626-2631. doi: $10.1073 /$ pnas. 0409848102

Emory-Tibet Science Initiative (2021). Robert A. Paul Emory-Tibet Science Initiative (ETSI). Available online at: https://tibet.emory.edu/programoverview.html (accessed July 28, 2021).

Gruber, M. J., Gelman, B. D., and Ranganath, C. (2014). States of curiosity modulate hippocampus-dependent learning via the dopaminergic circuit. Neuron 84, 486-496. doi: 10.1016/j.neuron.2014.08.060

Hamann, S. (2001). Cognitive and neural mechanisms of emotional memory. Trends Cogn. Sci. 5, 394-400. doi: 10.1016/S1364-6613(00)01707-1

Honey, C. J., Thompson, C. R., Lerner, Y., and Hasson, U. (2012). Not lost in translation: neural responses shared across languages. J. Neurosci. 32, 15277-15283. doi: 10.1523/JNEUROSCI.1800-12.2012

Klassen, S. (2010). The relation of story structure to a model of conceptual change in science learning. Sci. Educ. 19, 305-317. doi: 10.1007/s11191-009-9212-8

Lang, J. (2020). Distracted: Why Students Can't Focus and What You Can Do About It. New York, NY: Basic Books.

Mascaro, J. S., Kelley, S., Darcher, A., Negi, L. T., Worthman, C., Miller, A., et al. (2018). Meditation buffers medical student compassion from the deleterious effects of depression. J. Posit. Psychol. 13, 133-142. doi: $10.1080 / 17439760.2016 .1233348$

Mascaro, J. S., Rilling, J. K., Negi, L. T., and Raison, C. L. (2013). Compassion meditation enhances empathic accuracy and related neural activity. Soc. Cogn. Affect. Neurosci. 8, 48-55. doi: 10.1093/scan/nss095

Plato Republic (2009). "Books I, II, IV and the myth of the cave: from book VII," in Morality and the Good Life: An Introduction to Ethics through the Classical Sources. 5th Edn, Trans. G.M.A. Grube, eds C. R. Solomon, C. W. Martin, and W. Vaught (Boston: McGraw-Hill), 81-104.

Pratt, M. L. (1991). Arts of the Contact Zone. Profession 33-40.

Raichle, M. E. (2015). "The brain's default mode network," in Annual Review of Neuroscience, Vol 38, ed S. E. Hyman (Palo Alto: Annual Reviews), 433-447. doi: 10.1146/annurev-neuro-071013-014030

Regev, M., Honey, C. J., Simony, E., and Hasson, U. (2013). Selective and invariant neural responses to spoken and written narratives. J. Neurosci. 33, 15978-15988. doi: 10.1523/JNEUROSCI.1580-13.2013
Ryan, R. M., and Deci, E. L. (2020). Intrinsic and extrinsic motivation from a self-determination theory perspective: definitions, theory, practices, and future directions. Contemp. Educ. Psychol. 61, 101860. doi: 10.1016/j.cedpsych.2020.1 01860

Silbert, L. J., Honey, C. J., Simony, E., Poeppel, D., and Hasson, U. (2014). Coupled neural systems underlie the production and comprehension of naturalistic narrative speech. Proc. Natl. Acad. Sci. U. S. A. 111, E4687-E4696. doi: 10.1073/pnas.13238 12111

Simony, E., Honey, C., Chen, J., Lositsky, J., Yeshurun, Y., Wiesel, A., et al. (2016). Dynamic reconfiguration of the default mode network during narrative comprehension. Nat. Commun. 7, 12141. doi: 10.1038/ncomms 12141

Stephens, G. J., Silbert, L. J., and Hasson, U. (2010). Speaker-listener neural coupling underlies successful communication. Proc. Natl. Acad. Sci. U. S. A. 107, 14425-14430. doi: 10.1073/pnas.1008662107

Tikka, P., Kauttonen, J., and Hlushchuk, Y. (2018). Narrative comprehension beyond language: common brain networks activated by a movie and its script. PLoS ONE 13:e0200134. doi: 10.1371/journal.pone.0200134

Tyng, C. M., Amin, H. U., Saad, M., and Malik, A. S. (2017). The influences of emotion on learning and memory. Front. Psychol. 8, 1454. doi: 10.3389/fpsyg.2017.01454

Wilson, S. M., Bautista, A., and Mccarron, A. (2018). Convergence of spoken and written language processing in the superior temporal sulcus. Neuroimage 171, 62-74. doi: 10.1016/j.neuroimage.2017.12.068

Yates, F. A. (1966). The Art of Memory. Chicago. IL: University of Chicago Press.

Yeshurun, Y., Nguyen, M., and Hasson, U. (2021). The default mode network: where the idiosyncratic self meets the shared social world. Nat. Rev. Neurosci. 22, 181-192. doi: 10.1038/s41583-020-00420-w

Zajonc, A. (2013). Contemplative pedagogy: A quiet revolution in higher education. New Dir. Teach. Learn. 134, 83-94. doi: 10.1002/tl.20057

Conflict of Interest: The authors declare that the research was conducted in the absence of any commercial or financial relationships that could be construed as a potential conflict of interest.

The handling editor declared a past co-authorship with one of the authors KG.

Publisher's Note: All claims expressed in this article are solely those of the authors and do not necessarily represent those of their affiliated organizations, or those of the publisher, the editors and the reviewers. Any product that may be evaluated in this article, or claim that may be made by its manufacturer, is not guaranteed or endorsed by the publisher.

Copyright (c) 2022 Black, Kazama, Gyatso and Dema. This is an open-access article distributed under the terms of the Creative Commons Attribution License (CC BY). The use, distribution or reproduction in other forums is permitted, provided the original author(s) and the copyright owner(s) are credited and that the original publication in this journal is cited, in accordance with accepted academic practice. No use, distribution or reproduction is permitted which does not comply with these terms. 